\title{
A Comparative Study on Insect Longevity: Tropical Moths Do Not Differ From Their Temperate Relatives
}

\section{Sille Holm ( $\nabla$ sille.holm@ut.ee )}

University of Tartu: Tartu Ulikool https://orcid.org/0000-0002-2000-4899

Ants Kaasik

University of Tartu: Tartu Ulikool

Juhan Javoiš

University of Tartu: Tartu Ulikool

Freerk Molleman

Adam Mickiewicz University: Uniwersytet im Adama Mickiewicza w Poznaniu

Toomas Tammaru

University of Tartu: Tartu Ulikool

\section{Research Article}

Keywords: lifespan, ageing, longevity, phylogenetic comparative methods, insect, Lepidoptera

Posted Date: July 13th, 2021

DOl: https://doi.org/10.21203/rs.3.rs-685956/v1

License: (c) (i) This work is licensed under a Creative Commons Attribution 4.0 International License.

Read Full License

Version of Record: A version of this preprint was published at Evolutionary Ecology on January 7th, 2022.

See the published version at https://doi.org/10.1007/s10682-021-10150-9. 


\section{Abstract}

If the evolutionary determinants of longevity were mainly extrinsic, related species from different habitats should systematically differ in individual lifespans. Comparative studies of insects can significantly contribute to understanding the evolution of lifespan, as the trait can feasibly be measured in a high number of species. We recorded adult longevities for 110 species of geometrid moths from a tropical community. Comparative analyses based on an original phylogenetic reconstruction were applied to reveal the correlates of species-specific values of lifespan. Larger moth species were found to live longer, and females tended to have shorter lifespans than males. Average adult lifespans in tropical geometrids, and the relationships of lifespan with other variables, were found to be highly similar to those reported for their temperate region relatives. The among-region similarity leads to the conclusion of the dominance of intrinsic (physiological) determinants of longevity over the extrinsic (ecological) ones: the contrasting environments of tropical and temperate forests have not produced detectable differences in moth longevities.

\section{Introduction}

Longevity is certainly one of the most intensively studied life history traits. Nevertheless, besides research on human longevity (Kirkwood 2005; Hulbert et al 2007; Aravinthan 2015; Beaulieu et al 2015; Ziegler et al 2015), studies of ageing have mostly focused on just a few other model organisms (Ricklefs 2008; Austad 2010; Jones et al 2014). While it is widely acknowledged that multi-species comparisons are valuable in complementing such in-depth studies, methodologically up-to-date phylogenetic comparative analyses of longevity have not been widely employed (Holmes and Kristan 2008; but see e.g. Minias and Podlaszczuk 2017; Wilkinson and Adams 2019).

Among-species differences in longevity may be viewed as caused by a combination of intrinsic or 'physiological' factors and extrinsic or 'ecological' factors. The 'physiological explanation' views longevity as a side effect of body size. In particular, larger-bodied vertebrate species have long been known to live longer (Aristotle 350 BC; Prothero and Jürgens 1987; Healy et al 2014 and references therein; Scharf et al 2015; Stark and Meiri 2018). Metabolic rate is commonly believed to constitute the link between body size and longevity, owing to the fact that larger organisms generally have slower metabolism (Kleiber's law: e.g. McMahon 1973). Indeed, the negative relationship between metabolic rate and body size has turned out to be strikingly universal across species (reviewed in e.g. Reich et al 2006).

According to the 'ecological explanation', longevity has primarily evolved in response to extrinsic mortality. Ageing may arise in evolution simply because natural selection is weak on traits expressed beyond ages which are usually reached in nature, the relationship being reinforced by trade-offs between such traits and earlier fitness (Medawar 1952; Williams 1957; see also Kirkwood and Austad 2000; Reznick et al 2004; Chen and Maklakov 2012; Kimber and Chippindale 2013). Spatial and temporal distribution of the resources may have an additional role. In particular, organisms living under unpredictable conditions, e.g. species of harsh environments where the periods of favourable weather 
may be transient and the sources of food unstable, are to invest little resources in their own survival (Vinogradov 1998). Such animals are therefore expected to be shorter-lived (Peterson and Nilssen 1998) and to have a less durable physiological design. Contrary to that, species from more stable environments with more abundant adult food sources may evolve extended longevity because they are not limited by stored reserves (Dunlap-Pianka et al 1977; Carey 2001; Molleman 2009).

Extraordinary diversity of insects remains little used in phylogenetic comparative studies (Mayhew 2018), perhaps largely due to scarcity of comparable data. This also applies to studies on longevity. Indeed, gathering comparable data for global multi-species analyses of insect lifespans under natural conditions appears nearly impossible due to the typically small body size and high mobility of these animals (see also Zajitschek et al 2020). This problem can be mitigated by recording lifespans in a controlled laboratory environment, where longevity can feasibly be measured in a high number of species.

The few existing phylogenetic comparative studies on insect longevity have mostly focussed on the effects of body size, and thereby primarily on the physiological explanation of longevity. Beck (2008) detected a weak positive effect of body size on adult longevity in rainforest butterflies, Holm et al (2016) reported larger geometrid moths to live longer, while others have failed to find an effect of body size in some other lepidopterans (Jervis et al 2007b), hymenopteran parasitoids (Blackburn 1991), and odonates (Sherratt et al 2011). Addressing the ecological determinants of longevity in insects appears to be rare (see, however, Jervis et al 2007b; Beck and Fiedler 2009; Sherratt 2011). In an earlier study, we failed to detect the predicted effects of ecological factors such as the degree of host-plant specialisation and phenology (Holm et al 2016). However, the power of our analyses might have been low due to the limited variation in the values of the environmental parameters (as the study was restricted to species of temperate forest zone). Thus, ecological effects might manifest if the geographical scope of the comparisons would be extended, e.g. by including species from different climate zones, allowing for directional hypotheses to be tested for the comparisons among biomes.

Indeed, predation pressure on insects has been shown to increase towards lower latitudes (Roslin et al 2017). Accordingly, such geographical differences in mortality risk - the primary ecological factor suggested to shape longevity - could well have selected for latitudinal differences in the latter trait. However, other factors, such as stable supply of adult food in the tropical region (nectaring plants, fruits; Chapman et al 1999) might facilitate the evolution of longer adult lifespans in the Lepidoptera of tropical regions (see e.g. Molleman et al 2007). Also, the differences in the 'need' to have a long adult life may select for differences in longevity. For instance, generalism in larval host plant use might be associated with short adult lives. This is because, in the case of polyphagy, larval hosts are readily available for the ovipositing females and require less time to be located (Carey 2001; Prinzing 2003; Jervis et al 2007a). Higher larval host-plant specificity in the tropics (compared to temperate areas) has been reported for Lepidoptera (Dyer et al 2007; Forister et al 2015), so that, accordingly, there may be selection towards longer lifespans of the ovipositing females, which would allow them to cope with the challenge of locating host-plants among the diverse tropical vegetation. 
In the present study, we measured post-capture adult lifespan for 110 species of tropical geometrid moths (Lepidoptera: Geometridae). Species richness and feasibility of recording life-history traits in the laboratory makes this family of insects a promising target group for large-scale comparative analyses (Holm et al 2016, 2018; Heidrich et al 2018). We tested for the effects of body size and sex on lifespans of the moths, using wing wear and lab temperature as covariates. An original phylogenetic reconstruction (Holm et al 2018, 2019b) was involved to facilitate the comparative analysis. Further, we involved a comparable data set on longevity of temperate species (Holm et al 2016) to test for among-region differences. The results are discussed in the light of the physiological and ecological explanations for species-specific values of lifespan.

\section{Material And Methods}

\section{Lifespan data}

Residual (= post-capture) lifespans of 734 wild-caught adults (358 females, 376 males) representing 110 geometrid moth species were measured under the close-to-ambient laboratory conditions at a Makerere University Biological Field Station in Kibale National Park $\left(01^{\circ} \mathrm{N}, 30^{\circ} \mathrm{E}\right)$ in Uganda, East Africa. The study area represents species-rich, medium-altitude, moist, evergreen tropical forest (Struhsaker 1997). Moths were collected as adults by light trapping in the years 2011-2013. Sampling days $(N=141)$ were widely scattered over the study period to cover flight periods of different species. Samples were collected nonselectively, i.e. disregarding the physical condition of each individual. Collected moths were immediately placed individually in $50 \mathrm{ml}$ or $100 \mathrm{ml}$ transparent vials, depending on the individual's size.

The moths were kept in the vials in the laboratory at ambient temperature; the temperature was recorded hourly. The average temperature an individual experienced over its lifetime was $21.5^{\circ} \mathrm{C}$ (maximum $24.3^{\circ} \mathrm{C}$; minimum $19.4^{\circ} \mathrm{C}$ ). The moths were provided with food: $10 \%$ sugar solution offered on immersed tissue paper; the paper was fixed in place by hanging it between the vial and the lid. The tissue paper was remoistened with water daily, and again with sugar solution a week after the start of the experiment. Windows of the laboratory were covered with shades to darken the room, necessary to prevent escape flight towards the light and concurrent self-damage and exhaustion which might have reduced lifespan. The survival of each moth was checked on daily basis.

Male forewing length was used as the index of species-specific body size. Intact wild-caught specimens were used to measure wing length, the variable being defined as the distance between basal tip and apex of the forewing. Male rather than female wing length was selected as the index of species-specific body size, because females of some geometrid species have reduced flight ability, and disproportionately short wings (e.g. Snäll et al 2007; Holm et al 2016). However, it was not possible to obtain estimates of mean wing lengths for 46 species (of which 33 species were represented only by a single individual in the data) due to the lack of intact specimens. Those species were not included in the analyses involving the index of size. Temperature was included in the analyses as the mean temperature an individual experienced 
over its lifetime in the laboratory. Wing wear, a proxy of the moth's age at capture (Javoiš and Tammaru 2004), was recorded as a binary trait (1: a pristine individual, 2: noticeable loss of scales).

Relying on field-collected samples allowed us to include a high number of species (compared to e.g. a study based on laboratory reared individuals). Although the recorded residual lifespans of captive individuals do not directly represent the full potential of adult longevity - the trait shaped by natural selection - such values are still informative for comparative purposes (e.g. when comparing species and sexes; see Carey et al 2008 and Holm et al 2016 for discussion).

We further involved data on the longevity of temperate (Estonian) geometrids (43 species, 1281 individuals), obtained in an experiment with a similar design (described and analysed in Holm et al 2016). There was a methodological difference between the two data sets, however: the moths in Estonia were kept in thermoregulated chambers at two constant temperatures $\left(15^{\circ} \mathrm{C}\right.$ and $\left.23^{\circ} \mathrm{C}\right)$, whereas this was not possible in Uganda.

\section{Phylogenetic comparative analyses}

We used a phylogenetic tree of Geometridae constructed on the basis of the sequences of 8 genes (see Holm et al 2018, 2019b for details and references). Four subfamily-specific ultrametric trees were created using BEAST 1.8.1. (Drummond et al 2012) on the CIPRES Science Gateway (Miller et al 2010). Subsequently, the four ultrametric trees were combined into a single 373-species tree using the consensus.edges function from the R package phytools (Revell 2012). The tree was pruned to retain only the species included in the present study (Appendix 1; Appendix 2).

To identify the factors influencing species' lifespans in Uganda, we implemented trait-specific GLM models that account for phylogenetic autocorrelation. The predictors considered in the analyses were: body size, sex, wing wear, and temperature. As the number of individuals per species varied, it was critical to select a method of analysis which would properly weigh data points (species) by within-species sample sizes. To meet this requirement, we used analyses relying on Bayesian inference implemented in the R package rstan (Stan Development Team 2016; Holm et al 2018, 2019a for details of the approach). Given the Bayesian approach taken, the impact of a parameter as a factor influencing longevity was assessed on the basis of examination of its credible interval (Table 1). The same statistical approach was applied in a further analysis in which longevity of tropical and temperate geometrids was compared. As the applied Bayesian analyses are extremely demanding in terms of computing time (months), this analysis had to be limited to the subfamily Ennominae, to reduce the sample to manageable size. This is the largest subfamily in the data set ( $65 \%$ of Ugandan species), and also the only one in which both Ugandan and Estonian species are well represented (Appendix 2).

\section{Results And Discussion}

For 110 Ugandan geometrid moth species, post-capture lifespans were measured in the laboratory. The sample included 3 species from the subfamily Larentiinae; 72 species from Ennominae; 10 species from 
Sterrhinae; 26 species from Geometrinae. While the maximum sample size per species was 153 individuals, for many species we had only a few specimens and there were 43 singletons. On average the moths lived for 5.1 days (maximum was 17 days for a Cleora subcincta female) in the laboratory. For females, mean lifespan was 4.4 days (median 4 days); for males, mean lifespan was 5.8 days (median 6 days). On average, individuals in a pristine condition lived 1.31 times longer than the individuals with worn wings. When the lifespans of worn individuals were adjusted for wing wear, the average lifespan calculated over species means was 5.9 days (median 6 days; maximum 13.1 days; minimum 2.0 days).

These values are very close to those recorded for temperate (Estonian) geometrid moths (average over species means 6.7 days, median 6.8 days; Holm et al 2016, see also Fig. 2). For the subfamily Ennominae subjected to a formal analysis of the effect of region (Uganda vs. Estonia) was estimated to equal exactly zero (Table 2). In concert with the overall similarity, we detected no species with extraordinary long lifespans among tropical geometrid moths, which is in contrast to the pattern in butterflies (Molleman et al 2007).

The among-region similarity is in disagreement with some a priori expectations. Undeniably, the tropical environment is climatically more stable and offers more steady availability of adult food (nectaring plants, fruits; Chapman et al 1999) in comparison with the temperate region. This stability could be seen as permissive for the evolution of long adult lifespans. It might be hypothesized that selection caused by high predation pressure in tropical environments (Roslin et al 2017) balances the positive impacts of resource and climate stability, leaving therefore the net outcome of adult lifespan similar to that in the temperate zone. Estimates of adult mortality rates in the field are scarce for flying insects (see, however, Sang and Teder 2011; Tiitsaar et al 2013), and appear to be lacking for the tropical region completely, so that this hypothesis cannot be directly evaluated. Nevertheless, it appears rather unlikely that the putatively higher predation pressure in the tropics would exactly outweigh the stable availability of adult food there, and that this scenario applies for moths but not for butterflies. The similarity of adult lifespans of Estonian and Ugandan geometrids should thus rather be seen as a further piece of evidence of a limited role of ecological (vs. physiological) factors as determinants of species-specific longevities in insects (Holm et al 2016).

Indeed, consistent with the 'physiological hypothesis', larger species in our tropical sample showed longer adult lifespans (Table 1; Fig. 1). The largest moths (Colocleora sp. nr. potaenia, $34 \mathrm{~mm}$ wing length, average lifespan 7.1 days) lived 1.8 times, or 3.2 days, longer on average than the smallest ones (Scopula sp. SH01, 9 mm, average lifespan 3.9 days). A twofold increase in a linear measure of body size approximately corresponded to 1.2-fold increase in lifespan (Fig. 1); not so much different from the 1.3fold increase reported for temperate species (Holm et al 2016).

Sex had a credible effect on lifespan, with females showing 1.3 times shorter lifespans on average than males (Table 1; Fig. 2). A sexual difference in lifespan is not unexpected, as the tasks which male and female insects have to accomplish during their lifetimes differ substantially (e.g. Tammaru et al 1996; Gotthard et al 2000; Hunt et al 2004). However, no sex difference was detected in the temperate data set 
(Holm et al 2016). Such an asymmetry might be related to the limited seasonality of Ugandan forests which results in overlapping generations of insects, in contrast to the strictly seasonal life-cycles in the temperate climate. This could give the males more opportunities for multiple mating over an extended period of time (Tammaru et al 1996). An among-region difference in selective pressures on female lifespan appears less likely, as Estonian and Ugandan moths do not differ in egg production strategies (capital vs. income breeding, Holm et al 2019a), a major determinant of ecological traits in female moths (Davis et al 2016).

On the other hand, the among-region similarity in female lifespan may be viewed as further support to the earlier conclusion that the degree of host-plant specialization in Geometridae is actually rather similar between the two studied regions (Holm et al 2018, 2019b). Adult lifespan can be expected, and has been reported, to be negatively correlated with larval diet breadth (see Jervis et al 2007b and references therein, but see also Beck and Fiedler 2009; Holm et al 2016). The higher the degree of host specialization, the more time the adult female would need to find hosts for oviposition. The challenge of locating the few suitable host-plant species from a dense and diverse vegetation should, if anything, lead to the evolution of prolonged female lifespans in the tropics. This was, however, not the case.

As expected, individuals that experienced higher average temperatures showed shorter adult lifespans (Table 1; Fig. 2). The effect of temperature was moderate, with roughly a 0.4-day decrease in lifespan per a 1-degree increase in average temperature experienced over the life; the relationship was similar to that found in the temperate region (Fig. 2). It must be noted, however, that such quantitative between-region comparison should be treated with appropriate caution, because of methodological differences in measuring lifespans between the regions. Tropical moths were kept at ambient temperature (due to the lack of equipment in the tropics), but temperate species in thermo-regulated climate chambers (Holm et al 2016). Temperature was, however, accounted for in the comparative analyses to minimize temperaturecaused differences. Even if this did not eliminate the methodological differences completely, the qualitative conclusion appears straightforward: the tropical moths in our sample have rather similar adult lifespan patterns to their temperate relatives.

In summary, we found no evidence for extraordinary long lifespans in tropical geometrid moths. In particular, lifespans recorded for the tropical region were found not to differ considerably from those reported for the temperate region. A relationship between body size and longevity - similar to the one for temperate moths - was confirmed at the among-species level. These observations provide evidence that physiological rather than ecological factors shape the evolution of longevity in geometrid moths. In a more general context, we believe that the present study adds to the examples of how comparative studies on species-rich taxa hold the potential to address questions on the evolution of senescence. 
Table 1

Determinants of moth lifespan in the tropical region (Uganda, $\mathrm{N}=654$ individuals) based on a four-way phylogenetically informed GLM analysis relying on Bayesian inference ( $R$ package rstan). The baseline for categorical model parameters are: a) sex: male; b) wing wear: pristine individuals; other categories are compared against the baseline categories.

Estimates for $95 \%$ credible intervals of the posterior distribution of the difference which do not contain zero provide support for the model parameter: the effects of all the factors included in the model are supported.

\begin{tabular}{|lll|}
\hline Model parameter & Estimate & 95\% Credible interval \\
\hline Intercept & 2.386 & $(0.365 ; 3.815)$ \\
\hline Temperature & -0.082 & $(-0.116 ;-0.050)$ \\
\hline Sex: Female & -0.250 & $(-0.334 ;-0.169)$ \\
\hline Wing wear: worn & -0.196 & $(-0.307 ;-0.087)$ \\
\hline Male wing length $(\mathrm{mm})$ & 0.029 & $(0.010 ; 0.049)$ \\
\hline
\end{tabular}

Table 2

The effect of geographical location (Estonia vs Uganda, $\mathrm{N}=$ 1935 individuals) on moth lifespan based on Bayesian inference (R package rstan) for a subset of the data, the subfamily Ennominae. See Table 1 for further details.

\begin{tabular}{|lll|}
\hline Model parameter & Estimate & $95 \%$ Credible interval \\
\hline Intercept & 2.306 & $(0.137 ; 3.563)$ \\
\hline Region: Uganda & 0.000 & $(-0.113 ; 0.106)$ \\
\hline Temperature & -0.067 & $(-0.073 ;-0.058)$ \\
Sex: Female & -0.014 & $(-0.079 ; 0.043)$ \\
\hline Wing wear: worn & -0.284 & $(-0.343 ;-0.219)$ \\
\hline Male wing length $(\mathrm{mm})$ & 0.009 & $(-0.006 ; 0.024)$ \\
\hline
\end{tabular}

\section{Declarations}

\section{ACKNOWLEDGEMENTS}

We thank Boniface Balyeganira, Francis Katuramu Kanywanii, Edith Mbabazi, Harriet Kesiime, Isaiah Mwesige and Swaibu Katusabe for their invaluable assistance in the field and in the laboratory. We thank the Uganda Wildlife Authority (U.W.A.) and the Ugandan National Council for Science and Technology (U.N.C.S.T.) for permission to carry out the research. The authors declare that they have no conflict of interest. This work was supported by the Estonian Research Council grant PRG741. 
Funding: This work was supported by the Estonian Research Council grant PRG741.

Conflicts of interest/Competing interests: The authors have no conflict of interest to declare.

Ethics approval (include appropriate approvals or waivers): Not applicable

Consent to participate (include appropriate statements): Not applicable

Consent for publication (include appropriate statements): Not applicable

Availability of data and material (data transparency): All the data are available in Appendix 1 and Appendix 2.

Code availability (software application or custom code): Not applicable

Authors' contributions: FM, TT, JJ and SH conceived and planned the experiment. SH and FM carried out the experiment. SH and AK analysed the data. All authors discussed the results and contributed to the final manuscript.

\section{References}

Aravinthan A (2015) Cellular senescence: a hitchhiker's guide. Human Cell 28: 51-64

Aristotle (350 BC) On Longevity and the Shortness of Life. Translated by Ross GRT (1911), pp. 1-7

Austad SN (2010) Cats, "Rats," and bats: the comparative biology of aging in the 21st century. Integrated Computational Biology 50: 783-792

Beaulieu M, Geiger RE, Reim E et al (2015) Reproduction alters oxidative status when it is traded-off against longevity. Evolution 69: 1786-1796

Beck J (2008) Phylogenetic and ecological correlates with male adult life span of rainforest butterflies. Evolutionary Ecology 22: 507-517

Beck J, Fiedler K (2009) Adult life spans of butterflies (Lepidoptera: Papilionoidea + Hesperioidea): broadscale contingencies with adult and larval traits in multi-species comparisons. Biological Journal of the Linnean Society 96: 166-184

Blackburn TM (1991) A comparative examination of life-span and fecundity in parasitoid Hymenoptera. Journal of Animal Ecology 60: 151-164

Carey JR (2001) Insect biodemography. Annual Review of Entomology 46: 79-110 
Carey JR, Papadopoulos NT, Müller H-G et al (2008) Age structure changes and extraordinary lifespan in wild medfly populations. Aging Cell 7: 426-437

Chapman CA, Wrangham RW, Chapman LJ et al (1999) Fruit and flower phenology at two sites in Kibale National Park, Uganda. Journal of Tropical Ecology 15: 189-211

Chen H, Maklakov AA (2012) Longer life span evolves under high rates of condition-dependent mortality. Current Biology 22: 2140-2143

Davis RB, Javoiš J, Kaasik A, Õunap E et al (2016) An ordination of life-histories using morphological proxies: capital vs income breeding in insects. Ecology 97:2112-2124

Drummond AJ, Suchard MA, Xie D et al (2012) Bayian phylogenetics with BEAUti and the BEAST 1.7. Molecular Biology and Evololution 29: 1969-1973

Dunlap-Pianka H, Boggs CL, Gilbert LE (1977) Ovarian dynamics in Heliconiine butterflies: programmed senescence versus eternal youth. Science 197: 487-490

Dyer LA, Singer MS, Lill JT et al (2007) Host specificity of Lepidoptera in tropical and temperate forests. Nature 448: 696-699

Forister ML, Novotny V, Panorska AK et al (2015) The global distribution of diet breadth in insect herbivores. Proceedings of the National Academy of Sciences of the United States of America 112: 442447

Gotthard K, Nylin S, Wiklund C (2000) Mating opportunity and the evolution of sex-specific mortality rates in a butterfly. Oecologia 122: 36-43

Healy K, Guillerme T, Finlay S et al (2014) Ecology and mode-of-life explain lifespan variation in birds and mammals. Proceedings of the Royal Society B: Biological Sciences 281: 20140298

Heidrich L, Friess N, Fiedler K (2018) The dark side of Lepidoptera: Colour lightness of geometrid moths decreases with increasing latitude. Global Ecology and Biogeography 27: 407-416

Holm S, Davis RB, Javoiš J et al (2016) A comparative perspective on longevity: the effect of body size dominates over ecology in moths. Journal of Evolutionary Biology 29: 2422-2435

Holm, S, Javoiš, J, Kaasik, A et al (2019a) Size-related life-history traits in geometrid moths: a comparison of a temperate and a tropical community. Ecological Entomology 44: 711-716

Holm, S, Javoiš, J, Molleman, F et al (2019b) No indication of high host-plant specificity in Afrotropical geometrid moths. Journal of Insect Science 19: 1

Holm S, Javoiš J, Õunap E, et al (2018) Reproductive behaviour indicates specificity in resource use: phylogenetic examples from temperate and tropical insects. Oikos 127: 1113-1124 
Holmes DJ, Kristan DM (2008) Comparative and alternative approaches and novel animal models for aging research. Age 30: 63-73

Hulbert AJ, Pamplona R, Buffenstein R (2007) Life and death: metabolic rate, membrane composition, and life span of animals. Physiological Reviews 87: 1175-1213

Hunt J, Brooks R, Jennions MD et al (2004) High-quality male field crickets invest heavily in sexual display but die young. Nature 432: 1024-1027

Javoiš J, Tammaru T (2004) Reproductive decisions are sensitive to cues of life expectancy: the case of a moth. Animal Behaviour 68: 249-255

Jervis MA, Boggs CL, Ferns PN (2007a) Egg maturation strategy and survival trade-offs in holometabolous insects: a comparative approach. Biological Journal of the Linnean Society 90: 293-302 Jervis MA, Ferns PN, Boggs CL (2007b) A trade-off between female lifespan and larval diet breadth at the interspecific level in Lepidoptera. Evolutionary Ecology 21: 307-323

Jones OR, Scheuerlein A, Salguero-Gómez R et al (2014) Diversity of ageing across the tree of life. Nature 505: 169-173

Kimber CM, Chippindale AK (2013) Mutation, condition, and the maintenance of extended lifespan in Drosophila. Current Biology 23: 2283-2287

Kirkwood TB, Austad SN (2000) Why do we age? Nature 408: 233-238

Kirkwood TB (2005) Understanding the odd science of aging. Cell 120: 437-447

Mayhew PJ (2018) Comparative analysis of behavioural traits in insects. Current Opinion in Insect Science 27: 52-60

Minias P, Podlaszczuk P (2017) Longevity is associated with relative brain size in birds. Ecology and Evolution 7: 3558- 3566

McMahon T (1973) Size and shape in biology elastic criteria impose limits on biological proportions, and consequently on metabolic rates. Science 179: 1201-1204

Medawar PB (1952) An Unsolved Problem of Biology. HK Lewis, London

Miller JR, Koren S, Sutton G (2010) Assembly algorithms for next-generation sequencing data. Genomics 95: $315-327$

Molleman F, Ding J, Carey JR et al (2009) Nutrients in fruit increase fertility in wild-caught females of large and long-lived Euphaedra species (Lepidoptera, Nymphalidae). Journal of Insect Physiology 55: $375-83$ 
Molleman F, Zwaan BJ, Brakefield PM et al (2007) Extraordinary long life spans in fruit-feeding butterflies can provide window on evolution of life span and aging. Experimental Gerontology 42: 472-482

Peterson NA, Nilssen AC (1998) Late autumn eclosion in the winter moth Operophtera brumata: compromise of selective forces in life-cycle timing. Ecological Entomology 23: 417-426

Prinzing A (2003) Are generalists pressed for time? An interspecific test of the time-limited disperser model. Ecology 84: 1744-1755

Prothero J, Jürgens KD (1987) Scaling of maximal lifespan in mammals: a review, in: Woodhead AD, Thompson KH (Eds), Evolution of Longevity in Animals, Springer US, pp 49-74

Reich PB, Tjoelker MG, Machado J-Let al (2006) Universal scaling of respiratory metabolism, size and nitrogen in plants. Nature 439: 457-461

Revell LJ (2012) Phytools: An R package for phylogenetic comparative biology (and other things). Methods in Ecology and Evolution 3: 217-223

Reznick DN, Bryant MJ, Roff D et al (2004) Effect of extrinsic mortality on the evolution of senescence in guppies. Nature 431: 1095-1099

Ricklefs RE (2008) The evolution of senescence from a comparative perspective Functional Ecology 22: 379-392

Roslin T, Hardwick B, Novotny V (2017) Higher predation risk for insect prey at low latitudes and elevations. Science 356: 742-744

Sang A, Teder T (2011) Dragonflies cause spatial and temporal heterogeneity in habitat quality for butterflies. Insect Conservation and Diversity 4: 257-264

Scharf I, Feldman A, Novosolov M et al (2015) Late bloomers and baby boomers: ecological drivers of longevity in squamates and the tuatara. Global Ecology and Biogeography 24: 396-405

Sherratt TN, Hassall C, Laird RA et al (2011) A comparative analysis of senescence in adult damselflies and dragonflies (Odonata). Journal of Evolutionary Biology 24: 810-822

Snäll N, Tammaru T, Wahlberg N et al (2007) Phylogenetic relationships of the tribe Operophterini (Lepidoptera, Geometridae): a case study of the evolution of female flightlessness. Biological Journal of the Linnean Society 92: 241-252

Stan Development Team (2016) RStan: the R interface to Stan R package version $2141 \mathrm{http} / / / \mathrm{mc}-$ stanorg/

Stark G, Meiri S (2018) Cold and dark captivity: Drivers of amphibian longevity. Global Ecology and Biogeography 27: 1384- 1397 
Struhsaker TT (1997) Ecology of an African rain forest. University Press of Florida, Gainesville, Florida, USA

Tammaru T, Ruohomäki K, Saikkonen K (1996) Components of male fitness in relation to body size in Epirrita autumnata (Lepidoptera, Geometridae). Ecological Entomology 21: 185-192

Tiitsaar A, Kaasik A, Teder T (2013) The effects of seasonally variable dragonfly predation on butterfly assemblages. Ecology 94: 200-207

Vinogradov AE (1998) Male reproductive strategy and decreased longevity. Acta Biotheoretica 46: 157160

Wilkinson GS, Adams DM (2019) Recurrent evolution of extreme longevity in bats. Biology Letters 15: 20180860

Williams GC (1957) Pleiotropy, natural selection, and the evolution of senescence. Evolution 11: 398-411

Zajitschek F, Zajitschek S, Bonduriansky R (2020) Senescence in wild insects: Key questions and challenges. Functional Ecology 34: 26- 37

Ziegler DV, Wiley CD, Velarde MC (2015) Mitochondrial effectors of cellular senescence: beyond the free radical theory of aging. Aging Cell 14: 1-7

\section{Figures}




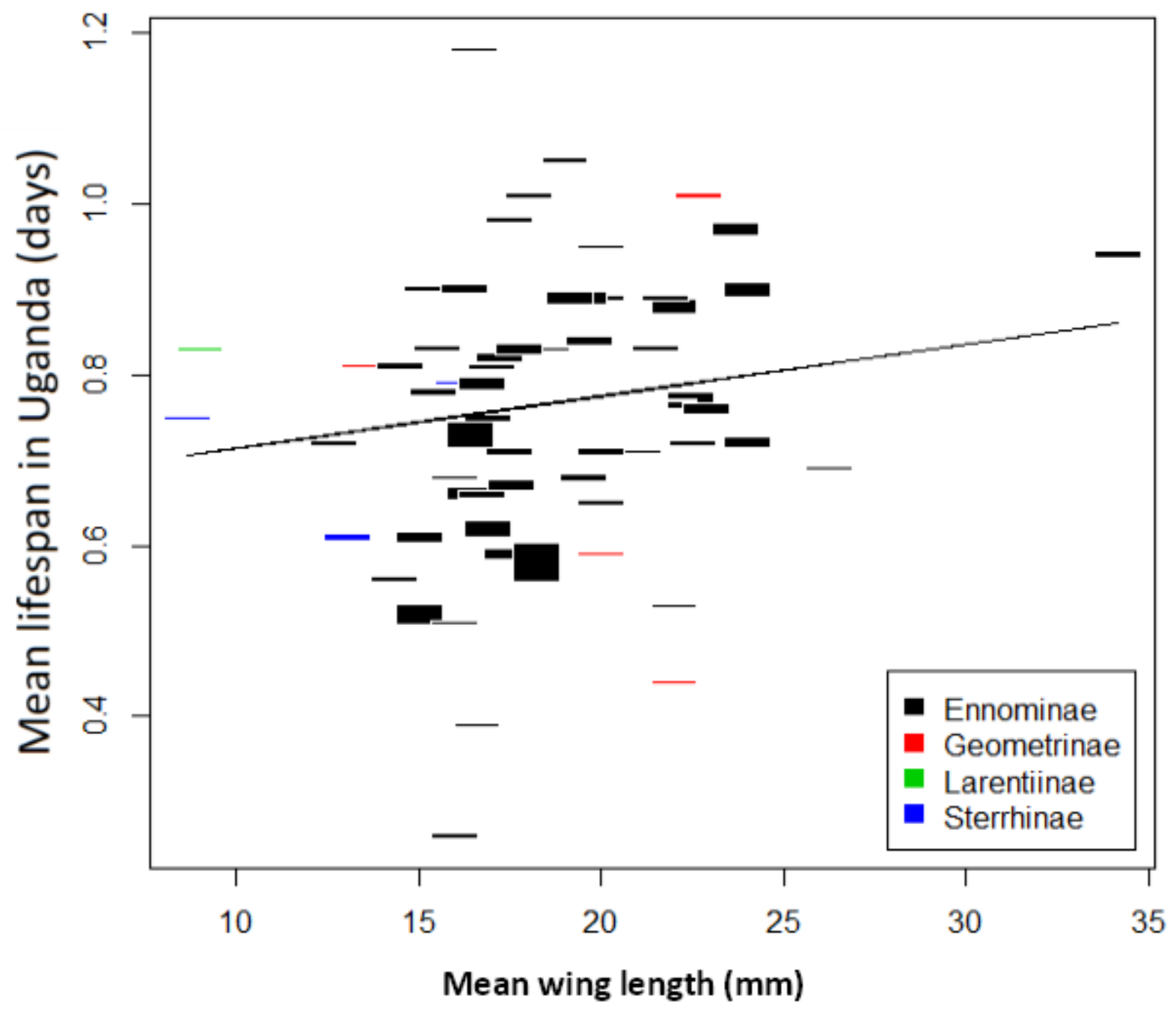

Figure 1

Relationship between species-specific average lifespan and male wing length $(\mathrm{mm})$. Each rectangle represents one species ( $\mathrm{N}=64$ species). The side lengths of the rectangles are proportional to the inverse of species-specific standard errors of respective variables. The indication of reliability is relative and should not be read against the scale on the axes. Non-phylogenetic linear regression line is added to visualise the results presented in Table 1. 


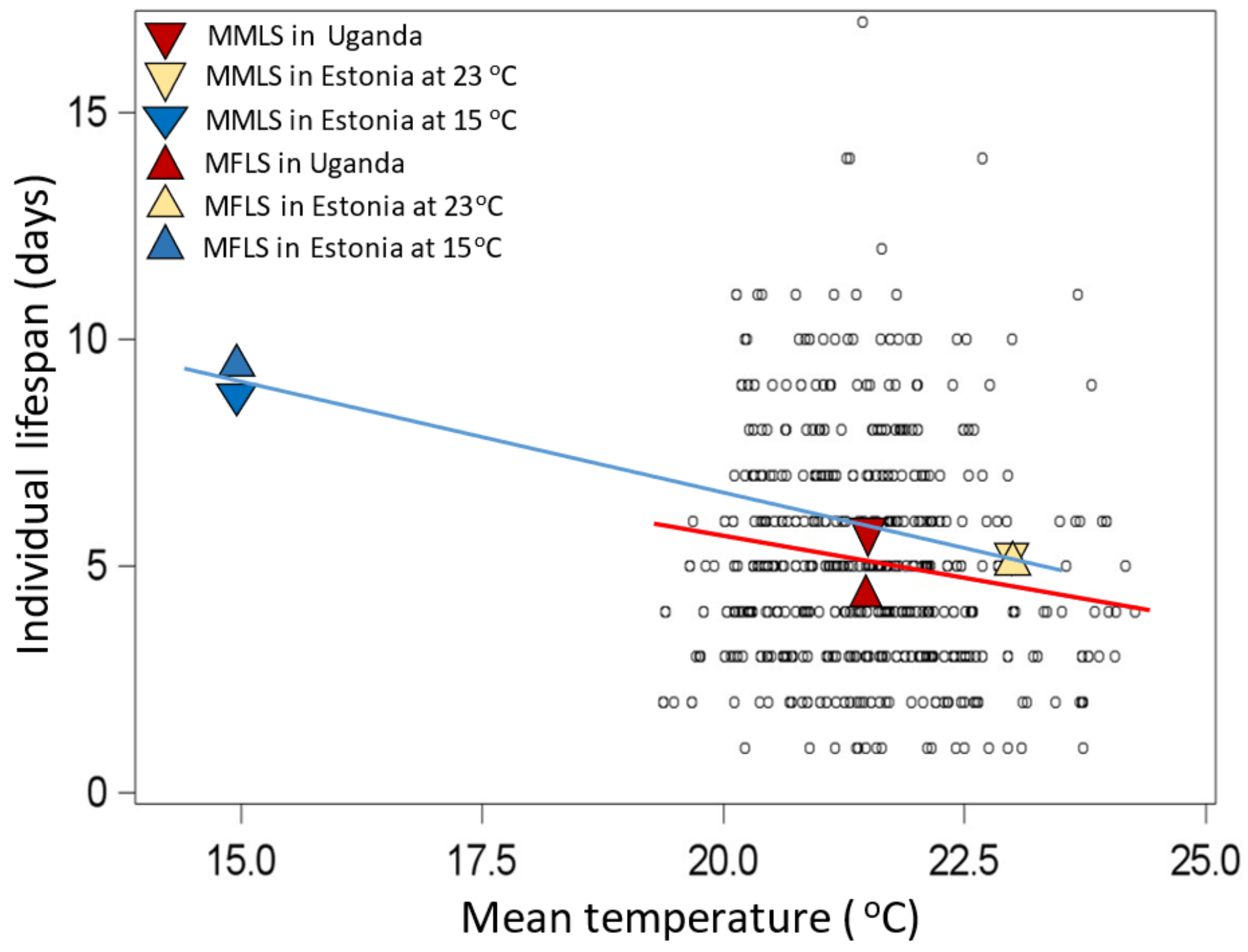

Figure 2

Relationship of lifespan and mean temperature in the Ugandan sample (red regression line; each spot represents a single individual). The red regression line is added to illustrate results presented in Table 1. Mean values for the temperate region lifespans and the blue regression line are based on the results published in Holm et al 2016. MMLS = mean male lifespan (days). MFLS = mean female lifespan (days).

\section{Supplementary Files}

This is a list of supplementary files associated with this preprint. Click to download.

- Appendix1.docx

- Appendix2.pdf 